\title{
Translation, cultural adaptation and psychometric evaluation of the Leganés cognitive test in a low educated elderly Brazilian population
}

Tradução, adaptação cultural e avaliação psicométrica da prova cognitiva de Leganés em uma população idosa brasileira com baixo nível educacional Vescia Vieira de Alencar Caldas ${ }^{1}$, Maria Victoria Zunzunegui², Aline do Nascimento Falcão Freire ${ }^{3}$, Ricardo Oliveira Guerra ${ }^{4}$

\begin{abstract}
Objective: To validate the Leganés cognitive test (LCT) for cognitive screening in low educated elderly Brazilians. Methods: The study sample was composed of 59 elderly residents from the city of Santa Cruz, in Brazil, with low schooling levels. Reliability was analyzed with a two-day interval between assessments, and concurrent validity was assessed using the Mini Mental State Examination (MMSE). Results: According to the LCT, the prevalence of dementia was $11.8 \%$. The scale items showed a moderate to strong correlation between domains ( $p<0.01)$, and inter-rater reliability exhibited ICC $=0.81,95 \% \mathrm{Cl}=0.72-0.88$. The factor analysis resulted in two factors: memory and orientation. Interscale agreement was considered poor $(k=-0.02)$, supporting the hypothesis of an educational impact on final MMSE scores. Conclusion: The results suggest that LCT has acceptable levels of reliability for use in low-educated Brazilian elderly.
\end{abstract}

Key words: cognition, dementia, elderly, education.

\section{RESUMO}

Objetivo: Validar a prova cognitiva de Leganés (PCL) para rastreio cognitivo em população idosa brasileira com baixa escolaridade. Métodos: A amostra foi composta por 59 idosos residentes no município de Santa Cruz, no Rio Grande do Norte. A confiabilidade foi analisada com intervalo de dois dias entre as avaliações; a validade concorrente foi feita utilizando o Mini-Exame do Estado Mental (MEEM). Resultados: De acordo com a PCL, a prevalência de demência foi de 11,8\%. Os itens da escala mostraram correlações de moderada à forte entre os domínios ( $p<0,01)$. A confiabilidade intraexaminador foi considerada boa, com ICC=0,81, CI95\%=0,72-0,88. A análise fatorial mostrou dois domínios distintos: memória e orientação. A concordância entre a PCL e o MEEM foi considerada ruim ( $k=-0,02)$, reforçando a hipótese da influência educacional no escore do MEEM. Conclusão: A PCL apresenta boa confiabilidade para uso em população idosa brasileira com baixo nível de escolaridade.

Palavras-Chave: cognição, demência, idoso, escolaridade.

The increased prevalence of dementia around the world has been highlighted as one of the consequences of population aging. Estimates suggest a worldwide population of about 24 million elderly people with dementia, approximately $60 \%$ of whom are living in developing countries ${ }^{1}$.
Many screening tools have been developed to identify the presence of cognitive impairment in the elderly, but their results are partially influenced by age, education, race, language, sensory limitations, and other systemic processes ${ }^{2,3}$. In addition, most of these tools have been developed in countries

\footnotetext{
${ }^{1}$ Master in Physical Therapy by the Federal University of Rio Grande do Norte (UFRN), Natal RN, Brazil;

${ }^{2} \mathrm{PhD}$ in Epidemiology, Professor at the Preventive Medicine Department of the University of Montreal, Canada;

${ }^{3}$ Master in Physical Therapy by the UFRN, Natal RN, Brazil;

${ }^{4} \mathrm{PhD}$ in Physical Activity and Health Sciences, University of Granada, Spain; Professor at the Physical Therapy Department of the UFRN, Natal RN, Brazil. Correspondence: Vescia Vieira de Alencar Caldas; Departamento de Fisioterapia; Avenida Senador Salgado Filho, 3.000 - Campus Universitário; $59078-970$ Natal RN, Brasil - E-mail: vesciacaldas@yahoo.com.br

Conflict of interest: There is no conflict of interest to declare.

Received11 May 2011; Received in final form 11 August 2011; Accepted 18 August 2011
} 
where education levels are high, which may produce falsepositive results when used in low-educated populations $s^{4,5}$.

In order to minimize such problems, several studies have been conducted to adjust cut-off values of existing instruments according to education levels, or to design new tools with a lower education impact in their total scores ${ }^{6-9}$. Cut-offs have been proposed in Brazil for some of the main cognitive screening instruments used in elderly ${ }^{10-13}$.

The Leganés cognitive test (LCT) was originally developed by Spanish researchers in the longitudinal study Envejecer em Leganés (Aging in Leganés) as a cognitive screening scale adapted to low-educated populations ${ }^{14}$. The LCT assesses basic cognitive ability functions and it shows strong reliability and validity in the studied populations ${ }^{5}$.

Using a cognitive assessment scale, which is both easy to administer and not influenced by education in the Brazilian population, may represent an alternative in preventing the educational biases of existing cognitive assessment scales. Thus, this study aims to culturally adapt the LCT order to use it in low educated elderly Brazilians, and to evaluate its psychometric properties by examining its reliability and validity.

\section{METHODS}

\section{Population and sample}

The sample comprised subjects from a study conducted in Brazil and in Canada to culturally adapt and evaluate physical and mental health assessment instruments for later use in a longitudinal study on aging and mobility in Canada, Brazil, and Colombia. This longitudinal study, funded by the Canadian Institutes of Health, seeks to provide greater knowledge on the development of functional disability in elderly with different epidemiological profiles, as well as to explain sex-related differences in mobility, to guide future community-based prevention strategies. To that end, a pilot study was conducted from October to December, 2009 in the city of Santa Cruz, with a population of 32,000 inhabitants, located $150 \mathrm{~km}$ from Natal, the capital of the State of Rio Grande do Norte, in Brazil.

\section{Sample calculation}

The sample for this study was calculated to estimate a Cohen's Kappa of 0.80 , with $80 \%$ power for a null hypothesis of 0.45 , for dichotomous measures of cognitive impairment. A sample of 64 subjects was considered enough to estimate an intraclass correlation coefficient close to 0.80 in a $95 \%$ confidence interval.

\section{Inclusion criteria}

Subjects were required to be from 65 to 74 years-old and they should not exhibit any severe disabilities. Disability was considered severe when the individual was incapable of performing the following activities unassisted: bathing, getting out of bed, eating, and using the toilet. Those who reported difficulties, but managed to perform these activities, were included in the study.

\section{Sampling strategy}

A random sample of elderly residents of the community was used. They were stratified according to the functional ability into two groups: full and reduced mobility. This criterion was established based on two questions in the questionnaire: difficulty of walking $1.5 \mathrm{~km}$ and climbing stairs. The ones who reported severe difficulty in at least one of the questions were considered as having reduced mobility. In addition, participants were equally divided according to sex, with 32 men and 32 women stratified into two age groups: 65-69 years old and 70-74 years old.

\section{Interviewer training}

Six interviewers were trained using the same training pattern based on videotapes, protocol instructions, and data forms.

\section{Cognitive assessment instruments LCT}

The LCT is a cognitive screening test developed in 2000 by Zunzunegui et al. ${ }^{14}$. It was designed to be easy to administer and to have no impact of schooling on its final scores. Test completion does not depend on the ability to write, calculate, draw, or conduct abstract thinking, allowing for an adequate cognitive screening in low-educated populations. It consists on the following areas:

- temporal orientation - date, day of week, time (0-3);

- spatial orientation: place and address (0-2);

- personal information: age, date of birth (day/month/ year), mother's maiden name (0-3);

- naming test: ability to name common objects presented in six drawings (0-6);

- immediate memory - remembering six objects shown in the drawings. The test starts with the following sentence: "Please tell me the names of the objects you saw in the drawings, and try to remember them because I will ask you again later". (0-6);

- late memory - five minutes after the naming test, the elderly were asked to recall the objects that were shown $(0-6)$;

- logical memory - immediate memory of a short story with six ideas (0-6).

The total score ranges from 0 to 32 , and can reach 0 to 8 in the orientation domain and 0 to 24 in the memory one. Higher scores are associated with better performance and the cognitive impairment cut-off is 22 points. The LCT has not been validated for the Brazilian population, but it was 
designed and administered in a population with a similar sociodemographic profile, particularly regarding education levels ${ }^{15-17}$.

\section{MMSE}

Two screening instruments for dementia and cognitive impairment were used in the cognitive assessment of subjects: the MMSE and the LCT.

The MMSE is a screening test widely used around the world to detect dementia and other cognitive disorders. The scale was validated for the Brazilian population by Bertolucci et al., in 1994, and differentiated cut-off adjustments have been proposed according to education levels. In the present study, the cut-off adapted to the elderly was used, which classifies individuals with scores below 23/24 as cognitively impaired ${ }^{11-13}$.

\section{Procedures}

\section{Translation and cross-cultural adaptation of the LCT}

Once authorized by the author, we obtained the original Spanish version of the scale. Back-translation and the bilingual method were used for translation and transcultural adaptation. Initially, two Spanish translators, aware of the research objectives, translated the instrument proposed by Zunzunegui et al. ${ }^{14}$, seeking content that was both semantically and conceptually equivalent to the original version. Later, both translators worked together and reached a consensus between their translations. A copy was made of the consensual translation, generating the first Portuguese version of the original instrument.

Then, the Portuguese version was sent to another translator (Spanish/Portuguese), who had no prior knowledge of the material to be back-translated. When this new Spanish version of the instrument was completed, the translators participating in the study's first phase carried out a comparative analysis between this and the original version in Spanish, and the translation of this consensus into Portuguese resulted in the second Portuguese version of the instrument.

The translation of the original text was proofread by researchers of the Brazilian version, who were proficient in Spanish and familiar with the contents in its source language, an essential condition for adequate translation.

\section{Data collection}

Data were collected in two home visits, where the researcher initially informed the elderly on the collection process. Those who agreed to participate in the study signed a free and informed consent form.

The first collection day consisted of applying the multidimensional questionnaire proposed in the pilot study, assessing both direct and self-reported physical health measurements through physical performance tests. The cognitive assessment scales (MMSE and LCT) were also administered on the first day. After a two-day interval, the elderly were reevaluated using the same tests applied in the first collection, with some simplifications. Cognitive performance and depression assessments were once again administered on the second collection day, without any changes to the previous procedure. For each subject both collections were made by a same researcher from the trained team, in order to determine intra-observer reliability.

The study was approved by the Research Ethics Committee of the Federal University of Rio Grande do Norte (UFRN), and all participants signed an informed consent before the evaluation.

\section{Data analysis \\ Descriptive analysis}

It was performed using measures of central tendency and dispersion (mean and standard deviation) for continuous variables, and absolute and relative frequency distributions were analyzed for categorical variables.

\section{Reliability and validity}

The Intraclass Correlation Coefficient was used to determine reliability levels. Internal consistency was verified by using Pearson's correlation for LCT items, and the factor analysis for the major domains that make up the scale.

In order to analyze instrument validity, Pearson's correlation was used to evaluate MMSE and LCT scores, while the Student's $t$-test was used to compare the means. Agreement between both cognitive scales regarding dementia screening was assessed using the kappa coefficient.

All data were analyzed with PASW 17.0, considering a significance level of $\mathrm{p}<0.05$.

\section{RESULTS}

The translation/back-translation processes occurred without any conflicts between the Portuguese and Spanish LCT items. With regards to cultural adaptation, no comprehension problems with the final Portuguese version of the instrument were observed among the studied subjects. Therefore, we consider the process of translation and cultural adaptation of the Brazilian version of LCT to be satisfactory.

The study sample was initially composed of 64 elderly, 5 of whom were excluded after the end of data collection due to incomplete questionnaires, resulting in a final sample of 59 subjects: 30 men and 29 women. Mean age was 69.5 \pm 2.9 years-old. Sociodemographic data for the sample are given in Table 1.

The mean and standard deviation of the cognitive scores obtained for each LCT domain are shown in Table 2. Mean total score on the LCT was $26.3 \pm 4.1$; this value is above the cut-off proposed for the screening of dementia for this 
Table 1. Clinical and sociodemographic characteristics of the sample.

\begin{tabular}{|c|c|c|c|}
\hline Variable & Categories & $n$ & $\%$ \\
\hline \multirow[t]{2}{*}{ Age } & $65-69$ years & 26 & 44.1 \\
\hline & 70-74 years & 32 & 54.2 \\
\hline \multirow[t]{2}{*}{ Sex } & Male & 30 & 50.8 \\
\hline & Female & 29 & 49.2 \\
\hline \multirow[t]{2}{*}{ Education } & Illiterate & 24 & 40.7 \\
\hline & Literate & 35 & 59.3 \\
\hline \multirow[t]{4}{*}{ Income (In Brazilian Reais) } & $<510$ & 5 & 8.5 \\
\hline & $510-1.530$ & 46 & 78.0 \\
\hline & $1.531-2.250$ & 4 & 6.8 \\
\hline & $>2.251$ & 4 & 6.8 \\
\hline \multirow[t]{2}{*}{ Depression } & Yes & 30 & 49.2 \\
\hline & No & 29 & 50.8 \\
\hline \multirow[t]{2}{*}{$\begin{array}{l}\text { Basic activities of daily } \\
\text { living }\end{array}$} & Independent & 48 & 81.4 \\
\hline & Dependent & 11 & 18.6 \\
\hline \multirow[t]{2}{*}{$\begin{array}{l}\text { Instrumental activities of } \\
\text { daily living }\end{array}$} & Independent & 41 & 69.5 \\
\hline & Dependent & 18 & 30.5 \\
\hline \multirow[t]{2}{*}{ Chronic conditions } & Yes & 39 & 66.1 \\
\hline & No & 20 & 33.9 \\
\hline \multirow[t]{2}{*}{ Falls last year } & Yes & 19 & 32.2 \\
\hline & No & 40 & 67.8 \\
\hline \multirow[t]{2}{*}{ Leganés Cognitive Test } & No impairment & 52 & 88.1 \\
\hline & Impaired & 7 & 11.8 \\
\hline \multirow[t]{2}{*}{$\begin{array}{l}\text { Mini Mental State } \\
\text { Examination }\end{array}$} & No impairment & 37 & 62.7 \\
\hline & Impaired & 22 & 37.2 \\
\hline
\end{tabular}

Source: Data collected by the researchers.

Note: 1 US\$ $\approx$ BR $\$ 1.65$.

Table 2. Scores of Leganés cognitive test (LCT).

\begin{tabular}{lcc}
\multicolumn{1}{c}{ LCT domains } & $\begin{array}{c}\text { Mean } \pm \text { standard } \\
\text { Deviation }\end{array}$ & Min-Max \\
\hline Naming test & $5.55 \pm 0.98$ & $0-6$ \\
Immediate memory & $5.01 \pm 1.18$ & $0-6$ \\
Late memory & $5.20 \pm 1.09$ & $0-6$ \\
Logical memory & $3.40 \pm 1.93$ & $0-6$ \\
Spatial orientation & $1.93 \pm 0.38$ & $0-2$ \\
Temporal orientation & $2.64 \pm 0.58$ & $0-3$ \\
Personal information & $2.52 \pm 0.56$ & $0-3$ \\
Total score & $26.67 \pm 3.30$ & $0-32$ \\
\hline
\end{tabular}

Source: Data collected by the researchers.

Table 3. Mini Mental State Examination (MMSE) scores.

\begin{tabular}{lccc}
\multicolumn{1}{c}{ MMSE domains } & $\mathrm{n}$ & $\begin{array}{c}\text { Mean } \pm \text { standard } \\
\text { deviation }\end{array}$ & Min-Max \\
\hline Temporal orientation & 59 & $4.49 \pm 0.85$ & $0-5$ \\
Spatial orientation & 59 & $4.67 \pm 0.50$ & $0-5$ \\
Immediate memory & 59 & $2.83 \pm 0.46$ & $0-3$ \\
Calculation and attention & 59 & $2.57 \pm 1.82$ & $0-5$ \\
Late memory & 59 & $1.49 \pm 1.04$ & $0-3$ \\
Visual constructive ability & 59 & $0.52 \pm 0.50$ & $0-1$ \\
Language & 59 & $6.81 \pm 1.33$ & $0-8$ \\
Total score & 59 & $23.44 \pm 3.63$ & $0-30$ \\
\hline
\end{tabular}

Source: Data collected by the researchers. instrument (22 points). Mean total score on the MMSE was 23.4 \pm 3.6 , oscillating between the case/no case classification proposed by Almeida, in 1998. Descriptive analysis of the MMSE scores is shown in Table 3.

\section{Reliability}

Internal consistency analysis using Pearson's correlation is depicted in Table 4. Significant correlations were found between memory and orientation domains $(\mathrm{p}<0.01)$. Correlations between immediate and late memory are strong, suggesting learning effect. Reliability analysis showed strong inter-rater reliability, with an ICC=0.81 (95\%CI=0.72-0.88).

\section{Concurrent validity}

Agreement between both cognitive scales regarding dementia screening was considered poor, as evidenced by the low kappa coefficient $(\mathrm{k}=-0.02)$, with no significant difference.

\section{Construct validity}

The LCT factor analysis resulted in two factors: memory and orientation, which explain slightly more than half (57\%) of the variance in the resulting score (Table 5). The first domain, considered as the Memory Domain, was composed of the following items: naming, immediate memory, late memory and logical memory. The second domain, consisting of the resulting scores in spatial orientation, temporal orientation and personal information, refers to what we consider the Orientation Domain.

\section{DISCUSSION}

Most cognitive scales are influenced by individual education level, making it difficult to screen true positives for dementia $^{18}$. Some authors have indicated a strong education impact on the total scores of important screening scales, such as the MMSE, even after cut-off adjustments according to education levels ${ }^{19}$.

The impact of sociocultural aspects, such as education level and environmental contexts, compromises the reliability and validity levels of current cognitive assessment tools for research in elderly populations. Moreover, the use of cognitive assessment tools adapted to the Brazilian reality is extremely important in the clinical field, since early detection of dementia in the elderly allows for preventive and therapeutic decision-making.

The possibility of conducting this study with an elderly population in a city in Northeast Brazil, whose socioeconomic and cultural characteristics are so peculiar, provided the necessary conditions to study validity and reliability for the Brazilian context. The successful translation and cultural adaptation of the LCT advances the use of such instruments, 
Table 4. Pearson correlation among Leganés cognitive test (LCT) items.

\begin{tabular}{|c|c|c|c|c|c|c|}
\hline \multirow{2}{*}{ LCT domains } & \multicolumn{6}{|c|}{ Correlations } \\
\hline & 2 & 3 & 4 & 5 & 6 & 7 \\
\hline Naming test & $0.46^{\star}$ & $0.51 *$ & 0.24 & -0.1 & -0.12 & 0.51 \\
\hline Immediate memory & & $0.78 *$ & 0.24 & 0.11 & -0.01 & 0.01 \\
\hline Late memory & & & $0.33 *$ & 0.16 & 0.14 & 0.07 \\
\hline Logical memory & & & & 0.21 & 0.2 & 0.1 \\
\hline Spatial orientation & & & & & $0.40 *$ & 0.2 \\
\hline Temporal orientation & & & & & & 0.1 \\
\hline Personal information & & & & & & \\
\hline
\end{tabular}

Source: Data collected by the researchers.

${ }^{*} \mathrm{p}<0.01$.

Table 5. Factor Analysis of Leganés cognitive test (LCT) domains.

\begin{tabular}{lcc} 
LCT domains & Factor 1 & Factor 2 \\
\hline Naming test & 0.66 & -0.43 \\
Immediate memory & 0.83 & -0.23 \\
Late memory & 0.9 & -0.1 \\
Logical memory & 0.55 & 0.26 \\
Spatial orientation & -0.29 & 0.74 \\
Temporal orientation & 0.2 & 0.75 \\
Personal information & 0.17 & 0.38
\end{tabular}

Source: Data collected by the researchers.

since it eliminates the cultural bias present in most cognitive assessments. No comprehension problems were observed among the subjects, allowing the instrument to be administered in a clear and reliable way.

In the present study, we used a sample of young-elderly with no history of falls and independent as to activities of daily living (ADLs). This population was chosen according to the criteria of a longitudinal study jointly conducted by researchers from three countries. Using a sample of healthy elderly made it difficult to detect cases of dementia, since cognitive decline is directly associated with increased age, disability and institutionalization ${ }^{20}$. However, even in a situation where dementia was not significantly observed, the results of the study on LCT reliability and validity indicated satisfactory psychometrics, especially regarding reproducibility of the values obtained.

Sociocultural and environmental factors did not alter reliability, showing similar results to those of the original ones that first developed and validated the scale. With regard to LCT composition, we observed a moderate to strong correlation between items related to memory and orientation domains. Therefore, LCT produces reliable results because it is a simple and direct measure for evaluating cognitive performance in the elderly ${ }^{5,14}$.

According to Herrera et al., the prevalence of dementia among the elderly in Brazil is $7.1 \%$, and may reach $12 \%$ for illiterate elderly ${ }^{21}$. The use of LCT and MMSE as screening tools in our study revealed dementia rates of 11.8 and $37.2 \%$, respectively, calculated according to an education-based classification.
Comparing PLC and MMSE cognitive screening results, we found a poor agreement rate (kappa close to zero). Moreover, significant differences between means were observed, suggesting discrepancies in classifying individuals with suspected dementia, and over-estimation of dementia when administering MMSE to a low-educated population, as found in other studies $^{22}$. The poorer performance in MMSE domains related to attention, calculation and language mastery reinforces the hypothesis of an education impact on total scores.

The LCT, which is based on the construction of its assessment items, is an instrument capable of assessing cognitive function in the elderly with no interference from education levels. Using factor analysis for the Brazilian version of LCT, we observed that domains related to memory and orientation clustered, forming two factors, as proposed in the study where the scale was originally developed. By including both of these important cognitive function domains, LCT can be easily administered and its validity ensured, since these items are amongst the most sensitive in the early detection of dementia and among the most specific in functional decline associations ${ }^{8}$.

Evaluating aspects related to memory and orientation appears to be most adequate for populations with low formal education levels ${ }^{23}$. Memory impairments derive from the process of cognitive aging, and complaints related to this ability are among the most common in the elderly ${ }^{24}$. Temporal orientation, however, is an early and highly specific marker of cognitive problems, besides being less dependent on education than other tasks, such as attention, calculation, spatial orientation, language, and drawing. Temporal orientation is a modifiable mortality risk predictor that may help in clinical practice; it could also help promoting health actions for the elderly population, aimed at reducing mortality by allocating the resources required to maintain and rehabilitate cognitive capacity ${ }^{24}$.

Based on these results, we believe that the Brazilian version of the LCT has acceptable levels of reliability for use in low-educated elderly individuals, given that it minimizes the education bias present in most cognitive assessment scales. Finally, we consider that developing screening tools adapted to the Brazilian reality may be a viable alternative to minimize or even prevent the education bias observed in the results of cognitive scales validated for Brazil. 


\section{References}

1. Scazufca M, Menezes PR, Araya R, et al. Risk factors across the life course and dementia in a Brazilian population: results from the Sao Paulo Ageing \& Health Study (SPAH). Int J Epidemiol 2008;37: 879-890.

2. Nasreddine ZS, Phillips NA, Bédirian V, et al. The Montreal Cognitive Assessment, MoCA: a brief screening tool for mild cognitive impairment. J Am Geriatr Soc 2005;53:695-699.

3. Folstein MF, Folstein SE, McHugh PR. Mini-Mental State. A pratical method for grading the cognitive status of patients for the clinical. $J$ Psychiatric Res 1975;12:189-198.

4. Salmon DP, Lange KL. Cognitive screening and neuropsychological assessment in early Alzheimer's disease. Clin Geriatr Med 2001;17:229-254.

5. de Yebenes MJG, Otero A, Zunzunegui MV, Rodriguez-Laso A, Sanchez-Sanchez F, Del Ser T. Validation of a short cognitive tool for the screening of dementia in elderly people with low educational level. Int J Geriatr Psychiatry 2003;18:925-936.

6. Liu HC, Chou P, Lin KN, et al. Assessing cognitive abilities and dementia in a predominantly illiterate population of older individuals in Kinmen. Psychol Med 1994;24:763-770.

7. Fillenbaum GG, Chandra V, Ganguli M, et al. Development of an activities of daily living scale to screen for dementia in an illiterate rural older population in India. Age Ageing 1999;28:161-168.

8. Senanarong V, Assavisaraporn S, Sivasiriyanonds N, et al. The IQCODE: an alternative screening test for dementia for low educated Thai elderly. J Med Assoc Thai 2001; 84:648-655.

9. Damasceno A, Delicio AM, Mazo DF, et al. Validation of the Brazilian version of mini-test casi-s. Arq Neuropsiquiatr 2005;63:416-421.

10. Atalaia-Silva KS, Lourenço RA. Translation, adaptation and construct validation of the Clock Test Among elderly in Brazil. Rev Saúde Pub 2008;42:2-7.

11. Almeida OP. Mini exame do estado mental e o diagnóstico de demência no Brasil. Arq Neuropsiquiatr 1998;56:605-612.

12. Bertolucci PHF, Brucki SMD, Campacci S, Juliano Y. O Mini-Exame do Estado Mental em uma populacao geral. Impacto da escolaridade. Arq Neuropsiquiatr 1994;52:1-7.
13. Brucki SMD, Nitrini R, Caramelli P, Bertolucci PHF, Okamoto IH. Sugestões para o uso do Mini-Exame do Estado Mental no Brasil. Arq Neuropsiquiatr 2003;61:777-781.

14. Zunzunegui MV, Gutiérrez Cuadra P, Béland F, Del Ser T, Wolfson C. Development of simple cognitive function measures in a community dwelling population of elderly in Spain. Int $J$ Geriatr Psychiatry 2000:15:130-140.

15. Béland F, Zunzunegui MV. El perfil de las incapacidades funcionales en las personas mayores. Rev Gerontol 1995;5:232-234.

16. Zunzunegui MV, Béland F, Llacer A, Leon V. Gender diferences in depressive symptoms among Spanish elderly. Soc Psychiatry Psychiatr Epidemiol 1998;33:195-205.

17. Béland F, Zunzunegui MV. Predictors of functional status in a population of community- dwelling elderly in Spain. Age Ageing 1999;28:153-159.

18. Yancik, R, Ershler W, Satariano W, Hazzard W, Cohen HJ, Ferrucci L. Report of the National Institute on Aging Task Force on Comorbidity.J Gerontol A Biol Sci Med Sci 2007;62:275-280.

19. Alvarado BE, Zunzunegui MV, Dek Ser T, Béland FD. Cognitive decline is related to education and occupation in a Spanish elderly cohort. Aging (Milano) 2002;14:132-142.

20. Oliveira DLC, Goretti LC, Pereira LSM. O desempenho de idosos institucionalizados com alterações cognitivas em atividades de vida diária e mobilidade: estudo piloto. Rev Bras Fisioter 2006;10:91-96.

21. Herrera EJR, Caramelli P, Silveira AS, Nitrini R. Epidemiologic survey of dementia in a community-dwelling Brazilian population. Alzheimer Dis Assoc Disord 2002;16:103-108.

22. Scazufca M, Almeida OP, Vallada HP, Tasse WA, Menezes PR. Limitations of the Mini-Mental State Examination for screening dementia in a community with low socioeconomic status. Eur Arch Psychiatry Clin Neurosci 2009;259:8-15.

23. Dickstein DL, Kabaso D, Rocher AB. Changes in the structural complexity of the aged brain. Aging Cell 2007;6:275-284.

24. Gong G, Rosa-Neto P, Carbonell F, Chen ZJ, He Y, Evans AC. Age- and gender-related differences in the cortical anatomical network. Neuroscience 2009;29:15684-15693. 